\title{
Roles of the Nuclear Receptors PXR1 and PXR2 in the Regulation of Cytochrome P450 3A11 Expression in Mouse Organs and Primary-Cultured Hepatocytes
}

\author{
Wataru Ochiai*1, Ryosuke Miki ${ }^{2}$, Mari Fukuda ${ }^{1}$, Haruka Kato ${ }^{1}$, Yuya Nakajo ${ }^{1}$, Ryuki Iimura ${ }^{1}$, Jo Hatogai ${ }^{1}$, \\ Shohei Harada', Satoshi Kitaoka ${ }^{1}$, and Kiyoshi Sugiyama ${ }^{2}$ \\ ${ }^{1}$ Department of Clinical Pharmacokinetics, Hoshi University, Japan
}

${ }^{2}$ Department of Functional Molecule Kinetics Hoshi University, Japan

Received: June 03, 2018; Published: June 12, 2018

*Corresponding author: Wataru Ochiai, Department of Clinical Pharmacokinetics, Hoshi University, Japan

\begin{abstract}
Pregnane X receptor (PXR) is a nuclear receptor that exists in forms such as PXR1 and PXR2. Activated PXR1 heterodimerizes with retinoid X receptor to increase the transcription of cytochrome P450 3A (CYP3A), a drug-metabolizing enzyme, by binding to the PXR biding site in nuclei. PXR2 is a splice variant of PXR1, which is localized to the nuclei and down regulates the transcription of CYP3A by PXR1. The present study investigated the roles of PXR1 and PXR2 in the regulation of CYP3A11 expression in adult mouse organs and primary cultured hepatocytes. In the liver and small intestine, which show high expression of CYP3A11 mRNA, PXR1 mRNA was highly expressed while PXR2 mRNA expression was low. In the lung, kidneys, heart, and stomach, which show low expression of CYP3A11 mRNA, both PXR1 and PXR2 mRNA were expressed at high levels. In the muscle and spleen, which express little CYP3A11 mRNA, both PXR1 and PXR2 mRNA were expressed at low levels. In primary-cultured hepatocytes, PXR1 mRNA was expressed at high levels on day 0 of culture, and markedly decreased beginning on day 1 . PXR2 mRNA was expressed at low levels on day 0, and gradually increased until day 5. CYP3A11 mRNA exhibited a different expression pattern from that of PXR1 or PXR2; expression peaked on day 0 and then gradually decreased. These results suggest that CYP3A11 expression is upregulated by PXR1 and downregulated by PXR2.
\end{abstract}

Keywords: PXR1; PXR2; CYP3A11; Hepatocyte; Liver

Abbreviations: VDR: Vitamin D receptor; PXR: Pregnane X Receptor; CAR: Constitutive Androstane Receptor; RXR: Retinoid X Receptor

\section{Introduction}

Nuclear receptors are ligand-dependent transcription factors that regulate the expression of target genes in response to various stimuli, including physiological factors and environmental factors Evans [1]. The results of genome sequencing have identified 48 nuclear receptors in humans and 49 nuclear receptors in mice Zhang [2]. The identified nuclear receptors include steroid hormone receptors that bind to biological substances such as glucocorticoid and estrogen, and nuclear receptors for which the ligands and physiological functions are unknown Glass [3]. Most of these nuclear receptors interact with lipid-soluble low molecular weight compounds and to contribute to drug metabolism, metabolic disorders such as diabetes and dyslipidemia, cancer cell proliferation, sex differentiation, and regeneration; therefore, nuclear receptors have gained attention as drug targets [4-12,14]. The expression of drug-metabolizing enzymes is regulated by nuclear receptors Sueyoshi \& Negishi [13]. Cytochrome P450 (CYP3A), an important drug metabolizing enzyme, is involved in the metabolism of more than $50 \%$ of currently available pharmaceutical preparations.

Changes in the expression level of CYP3A can alter the effects of many pharmaceutical preparations, affecting drug therapy. The expression level of CYP3A is regulated by nuclear receptors, including pregnane X receptor (PXR) [14-18], Constitutive Androstane Receptor (CAR) [19-21], and Vitamin D receptor (VDR) [22,23]. PXR is known to be highly expressed in the liver [24,25] and small intestine Cheng \& Klaassen [26]. This nuclear receptor is typically localized in the cytoplasm in the absence of ligands; however, once 
activated by ligand binding, it is transferred to the nucleus Glass [3], where it heterodimerizes with retinoid X receptor $\alpha$ (RXR囚) and activates the transcription of target genes $[27,28]$, by binding to the PXR response elements $[16,29,30]$. The other main target genes of PXR in addition to CYP3A include uridine diphosphate-glucuronosyltransferase, which has also been implicated in drug metabolism Buckley \& Klaassen [31].

PXR has recently been shown to exist as five different subtypes Gardner-Stephen et al. [32] in humans and two subtypes, PXR1 and PXR2, in mice Matic et al. [33]. PXR2 is a splice variant lacking a part of the amino acid sequence (exon 5) from PXR1. PXR1 is considered to have similar functions as PXR, which have been previously reported. PXR2 localizes to the nucleus but inhibits the activated transcription of target genes by PXR1 Matic et al. [33]. PXR1 is transferred from the cytoplasm to the nucleus in a ligand-dependent manner and activates the transcription of target genes, whereas PXR2 is localized to the nucleus and inhibits the activated transcription of target genes by PXR1. A luciferase assay using a CYP3A promoter demonstrated that the activated transcription of CYP3A11 mRNA by PXR1 was dose-dependently inhibited by PXR2 Matic et al. [33]. In most studies to date, however, drug-metabolizing enzymes were analyzed without considering the existence of PXR2, a splice variant of PXR1; thus, the functions of PXR in regulating drug-metabolizing enzymes remain unclear. In fact, it was reported that CYP3A was highly expressed in PXR knockout mice $[28,34]$, suggesting that PXR1 and PXR2 should be analyzed separately. The present study differentiated between PXR1 and PXR2 and investigated the roles of each nuclear receptor in CYP3A expression.

\section{Materials and Methods}

\section{Preparation of Primary Cultured Hepatocytes from Liver}

Mice received an intraperitoneal injection of pentobarbital sodium salt $(50 \mathrm{mg} / \mathrm{kg}$ ) and were laparotomized under anesthesia. Preperfusion was flushed through the hepatic portal vein for $10 \mathrm{~min}$ using Micro Tube Pump (MP-1000, EYELA, Tokyo Rikakikai Co. Ltd., Tokyo, Japan), followed by a collagenase solution for $15 \mathrm{~min}$ in the same manner as the preperfusion. The liver was then isolated and homogenized in D-MEM to prepare a hepatocyte solution. The hepatocyte solution was filtered through the Cell Strainer $(70 \mu \mathrm{m}$ Nylon, BD Biosciences, Franklin Lakes, NJ, USA) and centrifuged (H-18F, Kokusan Co. Ltd., Saitama, Japan) at 500冈g for $3 \mathrm{~min}$ at room temperature. After removing the supernatant, the cells were suspended in $30 \mathrm{ml}$ of 1:10 diluted HBSS and centrifuged at $500 \mathrm{\otimes g}$ for $3 \mathrm{~min}$ at room temperature.

This washing process was repeated three times. After removing the supernatant, the cells were suspended in $10 \mathrm{ml}$ of D-MEM to prepare a hepatocyte suspension. A $10 \mu \mathrm{l}$ aliquot of the hepatocyte suspension was mixed with $10 \mu \mathrm{l}$ of Trypan blue (Logos Biology, Annandale, VA, USA) to determine the cell count and cell viability using a cell counter (Logos Biology). In subsequent experiments, a hepatocyte suspension with a cell viability of $\geq 90 \%$ was used. The hepatocyte suspension was diluted with D-MEM (Sigma-Aldrich, St. Louis, MO, USA) to $1.0 \otimes 105 \mathrm{cell} / \mathrm{ml}$, seeded into a $10 \mathrm{~cm}$ colla- gen-coated dish (10ml/dish), and incubated for $1 \mathrm{hr}$ to enhance cell viability before the medium was replaced.

\section{Extraction of Total RNA}

To each organ, weighing approximately $30 \mathrm{mg}$, in a $2 \mathrm{ml}$ tube, $1 \mathrm{ml}$ of the TRI $\mathbb{R}$ reagent was added, and the sample was homogenized for 10s using a homogenizer (Physcotron NS-51, Microtec Co., Ltd., Chiba, Japan). The homogenate was vortexed (G-560, Scientific Industries, Bohemia, NY, USA) and allowed to stand at room temperature for $10 \mathrm{~min}$, and then $200 \mu \mathrm{l}$ of chloroform was added. The sample was vortexed and then allowed to stand at room temperature for $2 \mathrm{~min}$. The resultant solution was centrifuged (CF16RX, Hitachi Koki Co., Ltd., Tokyo, Japan) at $12,000 \otimes \mathrm{g}$ at $4^{\circ} \mathrm{C}$ for 15 min and a $400 \mu$ l aliquot of the supernatant was placed in a $1.5 \mathrm{~mL}$ microtube. To this sample, $400 \mu \mathrm{l}$ of 2-propanol was added, and the mixture was vortexed, allowed to stand at room temperature for $10 \mathrm{~min}$, and then centrifuged at $12,000 \mathrm{Qg}$ at $4^{\circ} \mathrm{C}$ for $10 \mathrm{~min}$. After removing the supernatant, the precipitate was suspended in $1 \mathrm{ml}$ of 70\% ethanol (7: 3 ethanol: ultrapure water) and vortexed, followed by centrifugation at $7500 \mathrm{Qg}$ at $4^{\circ} \mathrm{C}$ for $5 \mathrm{~min}$. The supernatant was discarded and the remaining ethanol was evaporated. To the precipitate, $300 \mu \mathrm{L}$ of ultrapure water was added to dissolve the RNA. Using an aliquot of the resultant solution, absorption spectra at $260 \mathrm{~nm}$ and 280nm were measured using the Nano Drop Lite (NDL, Thermo Fisher Scientific, Waltham, MA, USA) to determine the RNA concentration $(\mu \mathrm{g} / \mathrm{ml})$ and RNA purity.

\section{Synthesis of cDNA}

From $1.0 \mu \mathrm{g}$ of the total purified RNA, cDNA was synthesized using a high-capacity cDNA synthesis kit. For each sample, 2.0 $\mu \mathrm{l}$ of $10 \mathrm{X}$ reverse transcription (RT) buffer, $0.8 \mu \mathrm{L}$ of $25 \mathrm{X}$ dNTP mix, $2.0 \mu \mathrm{L}$ of 10X RT random primer, $1.0 \mu \mathrm{l}$ of Multi Scribe TM reverse transcriptase, $1.0 \mu \mathrm{L}$ of RNase inhibitor, and $3.2 \mu \mathrm{l}$ ultrapure water, which were all included in the high-capacity cDNA synthesis kit, were mixed on ice to prepare the 2X RT master mix. On a PCR plate, $10 \mu \mathrm{l}$ of $2 \mathrm{X}$ RT master mix and 1.0 $\mu \mathrm{g}$ of purified RNA were added and mixed. The mixture was incubated in an iQTM Thermal Cycler (582BR, Bio-Rad, Hercules, CA, USA) at $25^{\circ} \mathrm{C}$ for $10 \mathrm{~min}$ (Step 1), at $37^{\circ} \mathrm{C}$ for $120 \mathrm{~min}$ (Step 2), and at $85^{\circ} \mathrm{C}$ for $10 \mathrm{~min}$ (Step 3) for the reverse transcription reaction. The reaction mixture was diluted with TE buffer at a ratio of 1: 20 to prepare the cDNA solution.

\section{RT-PCR}

In each of the PCR 8-strip tubes, $0.1 \mu \mathrm{l}$ of TaKaRa Ex TaqTM (Shiga, Japan), $2.5 \mu$ l of $10 \mathrm{X}$ buffer, $2.0 \mu \mathrm{l}$ of Dntp mixture, $1.25 \mu \mathrm{l}$ of DMSO, $1.0 \mu \mathrm{l}$ of cDNA solution, $2.5 \mu \mathrm{l}$ of forward primer (20 X M) of the target gene, $2.5 \mu \mathrm{l}$ of reverse primer $(20 \mathrm{X} \mathrm{M})$ of the target gene, and $13.15 \mu \mathrm{l}$ of ultrapure water were added. DNA amplification was performed by repeating 30-45 cycles of denaturation at $94^{\circ} \mathrm{C}$ for $2 \mathrm{~min}$, followed by $98^{\circ} \mathrm{C}$ for $10 \mathrm{~s}$, annealing at $55-58^{\circ} \mathrm{C}$ for $30 \mathrm{~s}$, and elongation at $72^{\circ} \mathrm{C}$ for $30 \mathrm{~s}$, and elongation at $72^{\circ} \mathrm{C}$ for $90 \mathrm{~s}$, using the iQTM Thermal Cycler. The sequences of PXR1, PXR2, CYP3A11, and glyceraldehyde-3-phosphate dehydrogenase (GAPDH) used as the housekeeping gene were as follows: PXR1 and PXR2 forward, 5'-GAA AAG ATT GAG GCT CCA CC-3'; PXR1 and PXR2 reverse, 5'- 
GCG TCA ACT TCG CCA AA-3'; CYP3A11 forward, CGC CTC TCC TTG CTG TCA CA-3'; CYP3A11 reverse, 5'-CTT TGC CTT CTG CCT CAA GT; GAPDH forward, 5'-GGC AAA TTC AAC GGC ACA GT; GAPDH reverse, AGA TGG TGA TGG GCT TCC C-3'.

\section{Agarose Gel Electrophoresis}

A mixture of the PCR product and $1.0 \mu$ l of loading buffer was electrophoresed $(10 \mu \mathrm{l}$ per lane) on a $2.0 \%$ agarose gel containing ethidium bromide and TBE buffer at $100 \mathrm{~V}$ for $25 \mathrm{~min}$ at room temperature under light-shielded conditions. After electrophoresis, the agarose gel was imaged using a cooled CCD camera (LAS-3000 mini, Fuji Photo Film Co, Ltd., Tokyo, Japan) and the obtained image was analyzed using Multi Gauge V3.0 (Fuji Photo Film Co. Ltd.).

Results

\section{Expression Patterns of PXR1, PXR2, and CYP3A11 mRNA in Adult Mouse Organs}

The expression levels of PXR1, PXR2, and CYP3A11 mRNA in adult mice organs were measured by RT-PCR (Figure1). In the liver and small intestine, PXR1 mRNA was expressed at markedly high levels and PXR2 mRNA at markedly low levels. The expression levels of CYP3A11 mRNA in the liver and small intestine were much higher than in other organs. In the lung, kidney, heart, and stomach, PXR2 and PXR1 mRNA were highly expressed, while the expression levels of CYP3A11 mRNA were much lower than in the liver. In the skeletal muscle and spleen, PXR1 and PXR2 mRNA expression was low and similar, and CYP3A11 mRNA was minimally expressed.

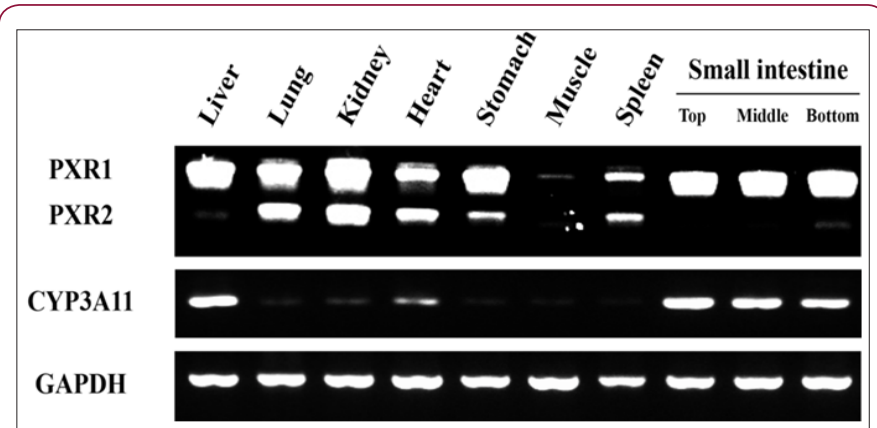

Figure 1: Expression patterns of PXR1, PXR2 and CYP3A11 mRNA in adult mouse organs.

Note: Organs were isolated from adult mice, and total RNA in the organs was purified and reverse transcripted. The expression levels of PXR1, PXR2 and CYP3A11 mRNA were measured by PCR.

\section{Altered Expression Levels of PXR1, PXR2, and CYP3A11 mRNA in Primary Cultured Hepatocytes}

The expression level of PXR1 mRNA was several-fold higher than that of PXR2 mRNA at the beginning of culture (day 0). On day 1, the expression level of PXR1 mRNA decreased to less than $10 \%$ of that at the beginning of culture and it remained low thereafter. The expression level of PXR2 mRNA, however, exhibited an approximately two-fold increase on day 1 compared with that at the beginning of culture, and further increased by approximately 3 -fold on day 5 . The expression level of CYP3A11 mRNA was extremely high on day 0 , but markedly decreased on day 1 , which continuous- ly declined to approximately $20 \%$ of that at the beginning of culture by day 5 (Figure 2). The expression levels of PXR and CYP3A on days $0,1,3$, and 5 were analyzed by immuno staining (Figure 3 ). Although we wished to differentiate between PXR1 and PXR2, there are no available antibodies to enable the individual recognition of PXR1 and PXR2; therefore PXR was analyzed using an antibody that recognizes both PXR1 and PXR2. The expression levels of both PXR and CYP3A in primary-culture hepatocytes were high on day 0 , but rapidly decreased on day 1 , with minimal signals observed on day 3 (Figure 3).

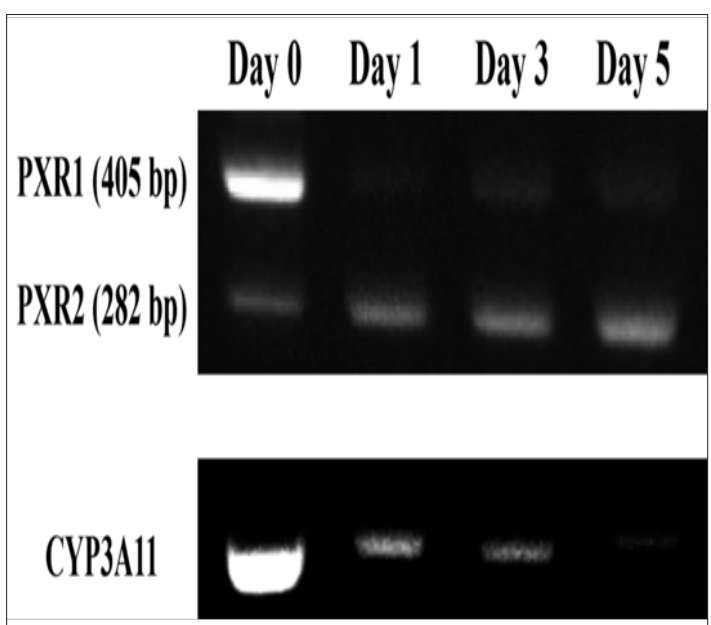

Figure 2: Changes over time in the expression levels of PXR1, PXR2 and CYP3A11 mRNA in primary cultured hepatocytes.

Note: From the primary cultured hepatocytes on day 0,1 , 3 and 5 of culture, mRNA was extracted to measure the expression levels of PXR1, PXR2 and CYP3A11 by RTPCR. The expression levels of PXR1 and PXR2 mRNA were determined assuming expression levels of PXR1 mRNA at the beginning of culture (day 0 ) to be $100 \%$. The expression level of CYP3A11 mRNA was determined assuming the expression level at the beginning of culture to be 100 .

MXY Day 0
Merge
Figure 3: Changes over time in PXR and CYP3A in
primary-cultured hepatocytes.
Note: The primary-cultured hepatocytes on days 0,1 ,
3 and 5 of culture were fixed and stained using an anti-
PXR antibody and anti-CYP3A antibody, to analyze the
expression patterns of PXR and CYP3A.




\section{Discussion}

CYP3A is a drug-metabolizing enzyme involved in the pharmacokinetics and appropriate use of drugs. Since PXR is an important nuclear receptor regulating the transcription of CYP3A, it has been extensively studied; it was recently revealed that the nuclear receptor PXR has different isoforms (Matic et al., 2010), and no studies have identified the individual PXR isoforms. Thus, the roles of PXR in the regulation of CYP3A expression remain unclear. In the present study, we determined the expression levels of PXR1, PXR2, and CYP3A mRNA in adult mice organs to conducted detailed examination of the roles of PXR in the regulation of CYP3A expression. In addition, endogenous PXR1 and PXR2 mRNA in primary-cultured hepatocytes were separately analyzed to evaluate the impact of changes in the expression of PXR1 and PXR2 mRNA on CYP3A11 expression. Our results revealed significantly higher expression of PXR1 mRNA and significantly lower expression of PXR2 mRNA in the liver and small intestine, with high expression of CYP3A11 mRNA. In comparison, the lung, kidneys, heart, and stomach, which showed low expression of CYP3A11 mRNA, showed high expression of both PXR1 and PXR2 mRNA (Figure 1). These findings indicate that the expression level of CYP3A11 was not only regulated by PXR1, which activates the transcription of CYP3A11 in a ligand-dependent manner, but also by PXR2, in differentiated cells (organs) with minimal proliferation. Unlike tissue cells, primary cultured hepatocytes show mitotic activity. In such hepatocytes, the expression pattern of CYP3A11 mRNA was not completely consistent with that of PXR1 mRNA and was not similar to that of PXR2 mRNA (Figure 2). These results suggest that the expression level of CYP3A11 is regulated by both PXR1 and PXR2 in primary cultured hepatocytes.

The expression levels of PXR1 and PXR2 were also analyzed on the protein level. Since there are no antibodies that can differentiate between PXR1 and PXR2, an existing anti-PXR antibody was employed. It has been reported that PXR1 is localized to the cytoplasm and nucleus and that PXR2 is localized only to the nucleus; thus, the signals observed in the cytoplasm by immunostaining of primary cultured hepatocytes can be attributed to PXR1 and the intensity of fluorescence signals in the nucleus was produced by a combination of activated PXR1 and PXR2 (Figure 3). Although a definite conclusion cannot be derived only from the results of the present study, the expression of CYP3A is considered to be regulated by the interaction between PXR1 and PXR2. If an antibody that recognizes the 41 amino acid residues present only in PXR1 can be produced, it may be possible to obtain more in-depth information.

To determine the expression level of CYP3A11, it is necessary to accurately determine the expression level of PXR, a transcription factor of CYP3A11. However, the results of the present study indicate that the exact expression level of CYP3A11 cannot be derived from the total PXR expression level without distinguishing between PXR1 and PXR2, which is commonly used to evaluate the expression level of CYP3A11. Our results also suggest that PXR1 and PXR2 have different functions in CYP3A11 expression; PXR1 activates the expression of CYP3A11, whereas PXR2 suppresses its expression.
Therefore, PXR1 and PXR2 should be individually analyzed to evaluate the function of PXR.

\section{Acknowledgment}

We thank Ms. Misa Iizuka, Ms. Konomi Oba, Mr. Osamu Kosaka, Ms. Saori Tomita, Ms. Mami Nakai, Mr. Hiroyuki Yoshida, and Ms. Tomoka Yasukawa for their technical assistance. We would like to thank Editage (www.editage.jp) for English language editing.

\section{References}

1. Evans RM (1988) The steroid and thyroid hormone receptor superfamily. Science 240(4854): 889-895.

2. Zhang Z, Burch PE, Cooney AJ, Lanz RB, Pereira FA, et al. (2004) Genomic analysis of the nuclear receptor family: new insights into structure, regulation, and evolution from the rat genome. Genome Res 149(4): 580-590.

3. Glass CK (1994) Differential recognition of target genes by nuclear receptor monomers, dimers, and heterodimers. Endocr Rev 15(3): 391407.

4. Biswas A, Pasquel D, Tyagi RK, Mani S (2011) Acetylation of pregnane $\mathrm{X}$ receptor protein determines selective function independent of ligand activation. BiochemBiophys Res Commun 406(3): 371-376.

5. Elcombe CR, Elcombe BM, Foster JR, Chang SC, Ehresman DJ, et al. (2012) Hepatocellular hypertrophy and cell proliferation in Sprague Dawley rats from dietary exposure to potassium perfluorooctanesulfonate results from increased expression of xenosensor nuclear receptors PPARalpha and CAR/PXR. Toxicology 293(1-3): 16-29.

6. Gao J, Xie W (2012) Targeting xenobiotic receptors PXR and CAR for metabolic diseases. Trends Pharmacol Sci 33(10): 552-558.

7. Habano W, Gamo T, Terashima J, Sugai T, Otsuka K, et al. (2011) Involvement of promoter methylation in the regulation of Pregnane $\mathrm{X}$ receptor in colon cancer cells. BMC Cancer 11: 81.

8. Kodama S, Negishi M (2013) PXR cross talks with internal and external signals in physiological and pathophysiological responses. Drug Metab Rev 45(3): 300-310.

9. Kumari S, Saradhi M, Rana M,Chatterjee S, Aumercier M, et al. (2015) Pregnane and Xenobiotic Receptor gene expression in liver cells is modulated by Ets-1 in synchrony with transcription factors Pax5, LEF-1 and c-Jun. Exp Cell Res 330(2): 398-411.

10. Niu Y, Wang Z, Huang H, Zhong S, Cai W, et al. (2014) Activated pregnane $\mathrm{X}$ receptor inhibits cervical cancer cell proliferation and tumorigenicity by inducing G2/M cell-cycle arrest. Cancer Lett 347(1): 88-97.

11. Niu Y, Wu Z, Shen Q, Song J, Luo Q et al. (2013) Hepatitis B virus X protein co-activates pregnane $\mathrm{X}$ receptor to induce the cytochrome P450 3A4 enzyme, a potential implication in hepatocarcinogenesis. Dig Liver Dis 45(12): 1041-1048.

12. Chen Z, Zhao B, Wang X, Fang X, Zhou J, et al. (2013) Shear stress activation of nuclear receptor PXR in endothelial detoxification. Proc Natl Acad Sci USA 110(32): 13174-13179.

13. Sueyoshi T, Negishi M (2001) Phenobarbital response elements of cytochrome P450 genes and nuclear receptors. Annu Rev PharmacolToxicol 41: 123-143.

14. El Sayed WM (2011) Effect of pregnane X receptor (PXR) prototype agonists on chemoprotective and drug metabolizing enzymes in mice. Eur J Pharmacol 660(2-3): 291-297.

15. Goodwin B, Redinbo MR, Kliewer SA (2002) Regulation of cyp3a gene transcription by the pregnane $\mathrm{x}$ receptor. Annu Rev PharmacolToxicol 42: 1-23. 
16. Istrate MA, Nussler AK, Eichelbaum M, Burk O (2010) Regulation of CYP3A4 by pregnane $\mathrm{X}$ receptor: The role of nuclear receptors competing for response element binding. BiochemBiophys Res Commun 393(4): 688-693.

17. Kliewer SA, Goodwin B, Willson TM (2002) The nuclear pregnane $X$ receptor: a key regulator of xenobiotic metabolism. Endocr Rev 23(5): 687-702.

18. Lamba JK, Lin YS, Schuetz EG, Thummel KE (2002) Genetic contribution to variable human CYP3A-mediated metabolism. Adv Drug Deliv Rev 54(10): 1271-1294.

19. DeKeyser JG, Laurenzana EM, Peterson EC, Chen T, Omiecinski CJ (2011) Selective phthalate activation of naturally occurring human constitutive androstane receptor splice variants and the pregnane $\mathrm{X}$ receptor. Toxicol Sci 120(2): 381-391.

20. Kodama S, Koike C, Negishi M, Yamamoto Y (2004) Nuclear receptors CAR and PXR cross talk with FOXO1 to regulate genes that encode drugmetabolizing and gluconeogenic enzymes. Mol Cell Biol 24(18): 79317940.

21. Tolson AH, Wang H (2010) Regulation of drug-metabolizing enzymes by xenobiotic receptors: PXR and CAR. Adv Drug Deliv Rev 62(13): 12381249.

22. Pavek P, Pospechova K, Svecova L, Syrova Z, Stejskalova L, et al. (2010) Intestinal cell specific vitamin D receptor (VDR)-mediated transcriptional regulation of CYP3A4 gene. BiochemPharmacol 79(2): 277-287.

23. Tayeb MT, Clark C, Haites NE, Sharp L, Murray GI, et al (2003) CYP3A4 and VDR gene polymorphisms and the risk of prostate cancer in men with benign prostate hyperplasia. Br J Cancer 88(6): 928-932.

24. Bertilsson G, Heidrich J, Svensson K, Jendeberg L, Sydow Backman M, et al. (1998): Identification of a human nuclear receptor defines a new signaling pathway for CYP3A induction. Proc Natl Acad Sci USA 95(21): 12208-12213.

25. Blumberg B, Sabbagh W, Juguilon H, Bolado J, Van Meter CM, et al. (1998) SXR, a novel steroid and xenobiotic sensing nuclear receptor. Genes Dev 12(20): 3195-3205.

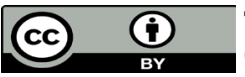

This work is licensed under Creative Commons Attribution 4.0 License

Submission Link: https://biomedres.us/submit-manuscript.php
26. Cheng X, Klaassen CD (2006) Regulation of mRNA expression of xenobiotic transporters by the pregnane $\mathrm{x}$ receptor in mouse liver, kidney, and intestine. Drug MetabDispos 34(11): 1863-1867.

27. Huss JM, Kasper CB (2000) Two stage glucocorticoid induction of CYP3A23 through both the glucocorticoid and pregnane $\mathrm{X}$ receptors. Mol Pharmacol 58(1): 48-57.

28. Staudinger JL, Goodwin B, Jones SA, Hawkins Brown D, MacKenzie KI, et al. (2001): The nuclear receptor PXR is a lithocholic acid sensor that protects against liver toxicity. Proc Natl Acad Sci USA 98(6): 3369-3374.

29. Frank C, Makkonen H, Dunlop TW, Matilainen M, Vaisanen S, et al (2005) Identification of pregnane $\mathrm{X}$ receptor binding sites in the regulatory regions of genes involved in bile acid homeostasis. J Mol Biol 346(2): 505-519.

30. Masuyama H, Suwaki N, Tateishi Y, Nakatsukasa H, Segawa T, et al (2005) The pregnane $\mathrm{X}$ receptor regulates gene expression in a ligand and promoter-selective fashion. Mol Endocrinol 19(5): 1170-1180.

31. Buckley DB, Klaassen CD (2009) Induction of mouse UDP-glucuronosyl transferase mRNA expression in liver and intestine by activators of arylhydrocarbon receptor, constitutive androstane receptor, pregnane $\mathrm{X}$ receptor, peroxisome proliferator-activated receptor alpha, and nuclear factor erythroid 2-related factor 2. Drug MetabDispos 37(4): 847-856.

32. Gardner Stephen D, Heydel JM, Goyal A, Lu Y, Xie W, et al. (2004) Human PXR variants and their differential effects on the regulation of human UDP-glucuronosyltransferase gene expression. Drug MetabDispos 32(3): 340-347.

33. Matic M, Corradin AP, Tsoli M, Clarke SJ, Polly P, et al (2010) The alternatively spliced murine pregnane $\mathrm{X}$ receptor isoform, mPXR (delta171-211) exhibits a repressive action. Int J Biochem Cell Biol 42(5): 672-682.

34. Schuetz EG, Strom S, Yasuda K, Lecureur V, Assem M, et al. (2001) Disrupted bile acid homeostasis reveals an unexpected interaction among nuclear hormone receptors, transporters, and cytochrome P450. J Biol Chem 276(42): 39411-39418.

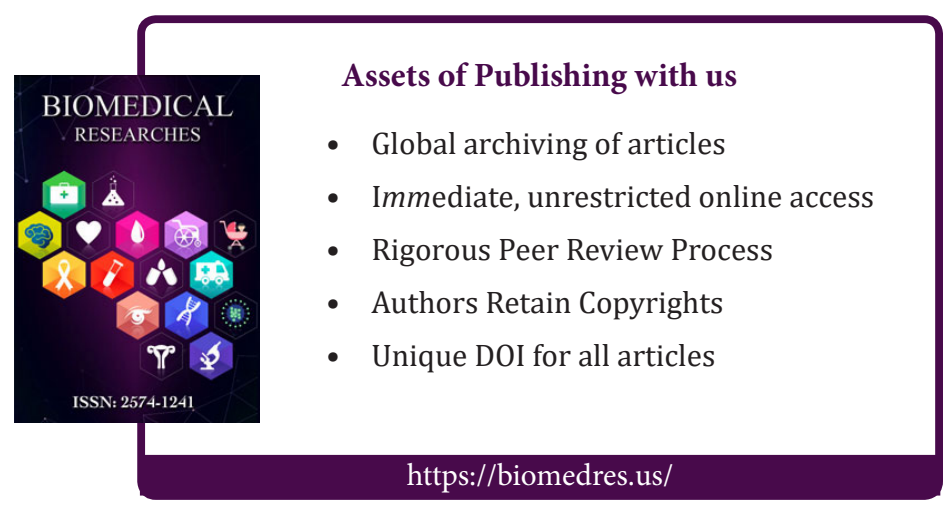

